\title{
Corrosion Protection of Steels by Conducting Polymer Coating
}

\author{
Toshiaki Ohtsuka \\ Faculty of Engineering, Hokkaido University, Kita 13-jo, Nishi 8-chome, Kita-ku, Sapporo 060-8628, Japan \\ Correspondence should be addressed to Toshiaki Ohtsuka, ohtsuka@eng.hokudai.ac.jp
}

Received 1 March 2012; Accepted 30 March 2012

Academic Editor: Rokuro Nishimura

Copyright (C) 2012 Toshiaki Ohtsuka. This is an open access article distributed under the Creative Commons Attribution License, which permits unrestricted use, distribution, and reproduction in any medium, provided the original work is properly cited.

The corrosion protection of steels by conducting polymer coating is reviewed. The conducting polymer such as polyaniline, polypyrrole, and polythiophen works as a strong oxidant to the steel, inducing the potential shift to the noble direction. The strongly oxidative conducting polymer facilitates the steel to be passivated. A bilayered PPy film was designed for the effective corrosion protection. It consisted of the inner layer in which phosphomolybdate ion, $\mathrm{PMo}_{12} \mathrm{O}_{40}{ }^{3-}(\mathrm{PMo})$, was doped and the outer layer in which dodecylsulfate ion (DoS) was doped. The inner layer stabilized the passive oxide and the outer possessed anionic perm-selectivity to inhibit the aggressive anions such as chloride from penetrating through the PPy film to the substrate steel. By the bilayered PPy film, the steel was kept passive for about $200 \mathrm{~h}$ in $3.5 \%$ sodium chloride solution without formation of corrosion products.

\section{Introduction}

Since the investigation of Shirakawa et al. on conducting polyacetylene, various applications of conducting polymer have been reported [1]. Utilization of the conducting polymer for corrosion protection coating is one of these applications, and many papers have been presented in the last decade. Preparation of polyacetylen was made by oxidation in gaseous phase; however, at present, the conducting polymers such as polyaniline (PAni), polypyrrole (PPy), and polythiophen (Pthio) in Figure 1 for the corrosion protection have been prepared by electrochemical oxidation in liquid phase.

For application of the conducting polymer to corrosion protection, DeBerry was firstly reported in 1985, who presented that the stainless steel covered by PAni was kept in the passive state for relatively long period in sulfuric acid solution [2]. Wessling then pointed out that the conducting polymer coating of polyaniline and polypyrrole possibly possessed self-healing properties, in which the passive oxide between the substrate metal and the conducting polymer could be spontaneously reformed at a flawed site by oxidative capability of the conducting polymer [3].

When anodic potentials are applied to electrodes covered by the conducting polymers shown in Figure 1 after the polymerization, the oxidative property is provided in addition to the conductivity. The ability of the conducting polymer to oxidize the substrate steels allows potential of steels to be shifted to the passive state, in which the steels are protected by the passive oxide formed beneath the conducting polymer. The application of the conducting polymer coating to the corrosion protection of steels was reviewed by Tallman et al. [4]. In this paper, the application of a bilayered conducting PPy to the protection of the steels is reviewed.

\section{Conducting Polymer}

Oxidative polymerization and the doping of anions into the polymer to provide the electronic conductivity have been reviewed by many authors, and here we briefly describe the process of PPy. When the electrode is anodically polarized in an electrolyte solution containing monomer of pyrrole (Py), the black polymer film can be formed on the electrode. The polymerization procedure is done without any difficulty, except for careful treatment of the electrolyte in which oxidation of the Py monomer by air should be avoided. The electrolyte should be thus deoxygenated by inert gas bubbling.

Figure 2 illustrates a model of the process for anodic polymerization of PPy proposed by Genies et al. [5]. Py monomer dissolved in the electrolyte donates an electron 


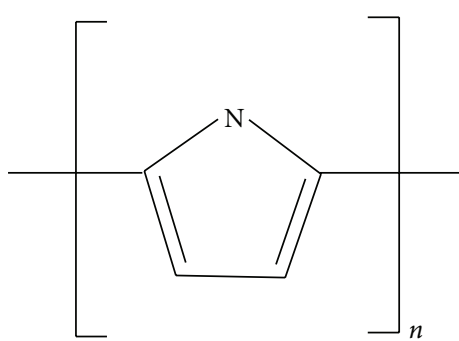

(a)

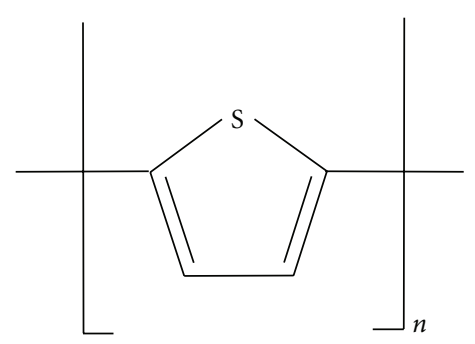

(b)

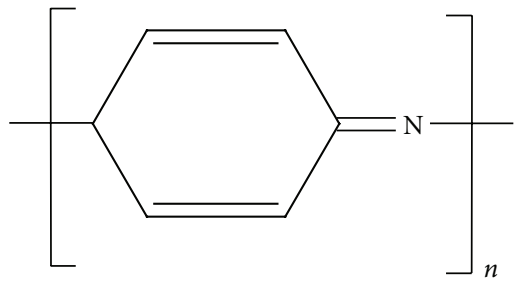

(c)

FIGURE 1: Typical conducting polymers: (a) polypyrrole (PPy), (b) polythiophen (PThio), and (c) polyaniline (PAni).

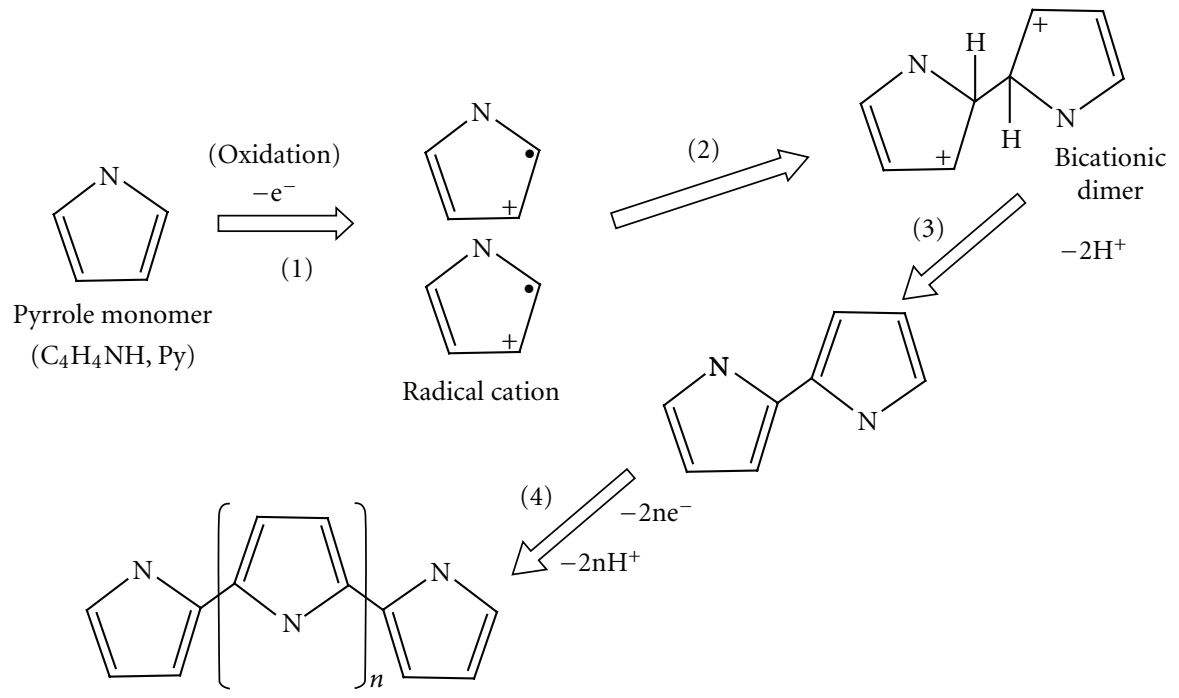

Neutral non-conducting

polypyrrole

FIGURE 2: Electropolymerization process of PPy.

into the electrode, resulting in formation of a radical-cation pair (step (1)). The radicals in Py are reacted with each other and two protons are removed from the reacted Py pair (step (2)), forming a dimer of Py (step (3)). After the formation of the radical-cation pair and the reaction between the radicals are repeated, the black PPy film is formed on the electrode (step (4)).

The neutral PPy thus formed with a conjugated chain does not possess any conductivity. To add the conductivity into the neutral PPy, further oxidation is required as shown in Figure 3. When the anodic potential is applied to the electrode, an electron is removed from $\pi$ electrons in the conjugated bond, yielding a pair of a radical and a positive charge (or cation) in the PPy backbone. This situation is called radical-cation state or polaron state. When the two radicals in the PPy are combined, the sites of single and double bond are replaced with each other and two cations remain in the PPy, the situation of which is called bication state or bi-polaron state. The cation thus formed in the PPy can move through $\pi$ electron clouds, yielding electronic conductivity in the PPy backbone.
With the removal of electrons from the PPy backbone, insertion of anions from the environmental electrolyte solution occurs to maintain neutrality of the PPy layer; that is, when the neutral state of PPy changes to the oxidative state, removal of electrons and doping of anions simultaneously take place. It is assumed that one positive charge (or cation) can be inserted in three or four Py units at maximum. When more positive charge is added, the PPy changes to overoxidation state and loses the conductivity.

\section{Corrosion Protection of Steels by Conducting Polymer of PPy}

3.1. Mechanism of Corrosion Protection. For the corrosion protection, two mechanisms have been proposed; one is the physical barrier effect, and the other is anodic protection. On the barrier effect, the polymer coating works as a barrier against the penetration of oxidants and aggressive anions, protecting the substrate metals. This effect is similar to paint coating which inhibits the substances from penetrating to 


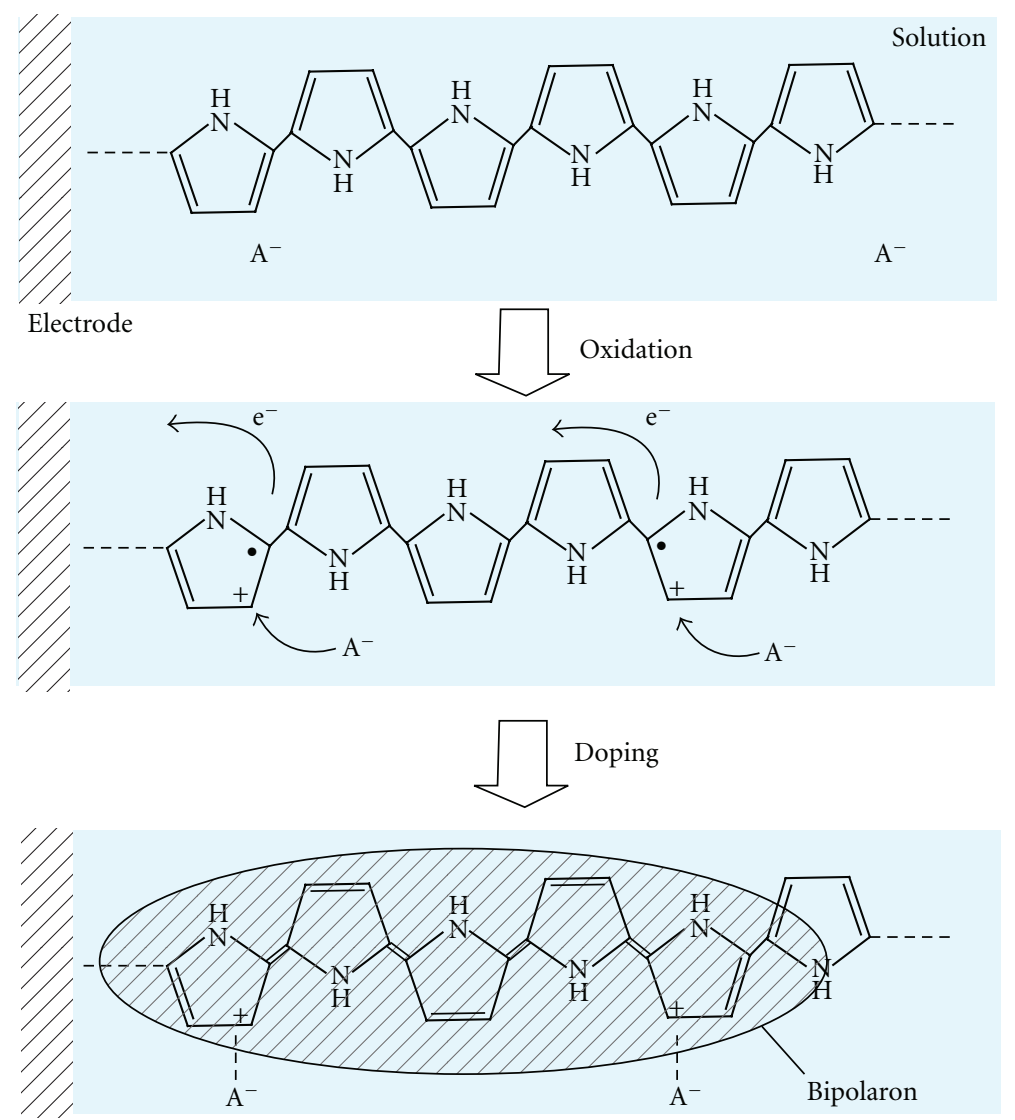

Figure 3: Electrochemical oxidation of neutral nonconducting PPy. During the oxidation, electron transfer from PPy to substrate steel and doping of anions from electrolyte solution to PPy simultaneously occur.

the substrate steel. On the anodic protection, the conducting polymer with the strongly oxidative property works as an oxidant to the substrate steel, potential of which is shifted to that in the passive state. In solution at neutral $\mathrm{pH}$, the corrosion potential (or open circuit potential in corrosion) of bare steel is located in the active potential region and the corrosion rate of the steel is usually relatively high. Owing to the coating of conducting polymer, the maximum current in the active-passive transition region was limited by the barrier effect, and then the potential can be easily shifted to the higher potential in the passive state by the strongly oxidative property of the conducting polymer (Figure 4). In the passive state, the corrosion rate of steel becomes much lower. It is assumed that both the barrier effect and the oxidative property induce the anodic protection. Finally, the potential of the substrate steel may be in agreement with a redox potential of the PPy layer in the following reaction, and thus, depends on the degree of oxidation state of the PPy layer.

$$
\begin{aligned}
\operatorname{PPy}^{n+} & \cdot\left(\frac{n}{x}\right) \mathrm{A}^{x-}+m \mathrm{e} \\
& \rightleftarrows \mathrm{PPy}^{(n-m)+} \cdot\left(\frac{n-m}{x}\right) \mathrm{A}^{x-}+\left(\frac{m}{x}\right) \mathrm{A}^{x-} \mathrm{aq} .
\end{aligned}
$$

The conductivity of the PPy layer affects the oxidative power which brings about the passive state. If the coating layer has little conductivity, the role of the coating as the oxidant is limited in the neighbourhood of the passive oxide. If the layer has enough high conductivity; however, the oxidant power of the whole layer is available and the power increases with the increase of the layer thickness.

The oxidation degree and the conductivity are assumed to decline with longer exposure to environment. If oxidants in the environment reoxidize the degraded PPy layer, the oxidation degree and conductivity can be recovered. When the oxidant in the environment, typically oxygen gas in air, can recover the PPy layer, the duration to maintain the oxidative power of the PPy layer can be prolonged and the passive state of the steel underneath the PPy layer can be kept for a longer period. The recovery process is illustrated in Figure 5.

3.2. Ion Exchange in the Conducting Polymer and Its Effect on Corrosion Protection. In the anodic protection, the largest problem is breakdown of passive oxide due to the attack of aggressive anions such as chloride and bromide ions in solution and the breakdown is followed by a large damage of localized corrosion of pitting and crevice corrosion. As contrasted with the cathodic protection, there is a large risk of the localized corrosion connected with the anodic protection. When we control the doping ions in the PPy layer, we possibly prevent penetration of the aggressive anions into the 


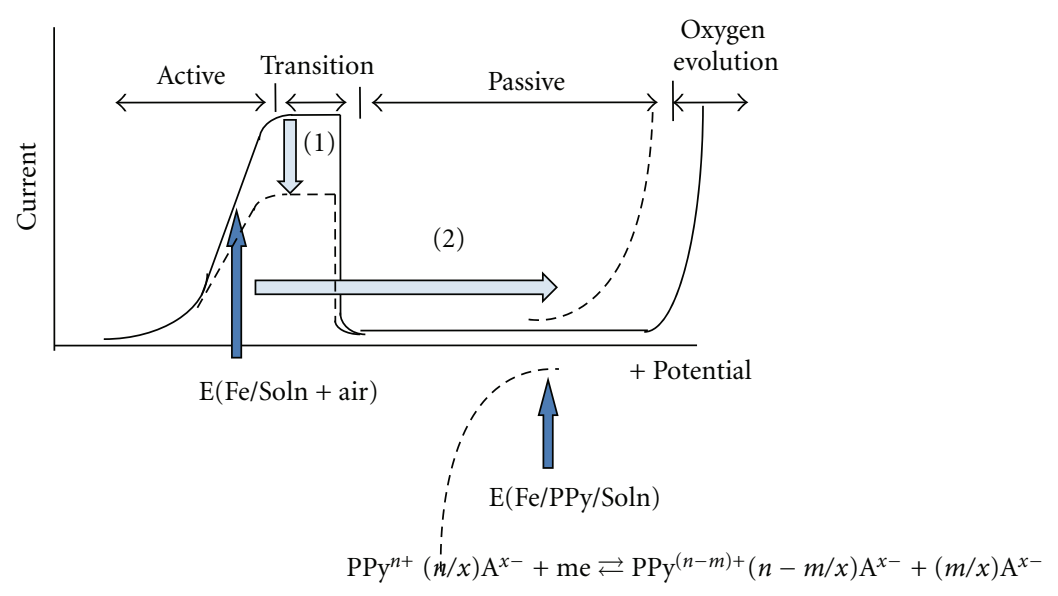

Role of oxidative-conductive polymer for corrosion prevention:

(1) Suppression of active dissolution $=$ barrier effect

(2) Potential shift by oxidative polymer = anodic protection

FIGURE 4: Potential-current relation of steels covered by oxidative conducting PPy. A barrier effect of PPy suppresses active dissolution of the steel and an oxidative property of PPy shifts the potential into passive state.

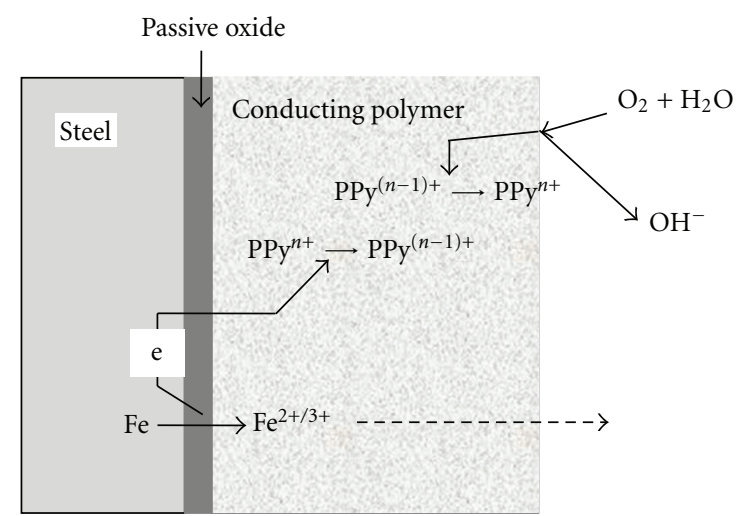

Figure 5: Degradation of oxidative property of PPy and recovery, which was done from reduction of oxygen on the PPy surface.

PPy layer. When the steels covered with the conducting PPy are immersed in the sodium chloride solution, the anions doped in the PPy can be exchanged with the chloride anions in the aqueous solution. The chloride anions penetrate the PPy to the substrate steels, and then induce the breakdown of the surface passive oxide film, followed by the pitting corrosion.

The mobility of the dopant anions in the PPy is affected by their mass and volume. When we adopted organic acid ions as the dopant ions in the PPy, they possessed enough large mass and volume to be immobile in the PPy. In general, organic acid anions with large mass are assumed to have small mobility and diffusion in the PPy layer. Accompanied with the oxidation and reduction of the PPy, small anions are doped into and dedoped out of the PPy, respectively, to maintain the neutrality, as described in reaction (1) and shown in Figure 6(a). When the mobility and diffusion of

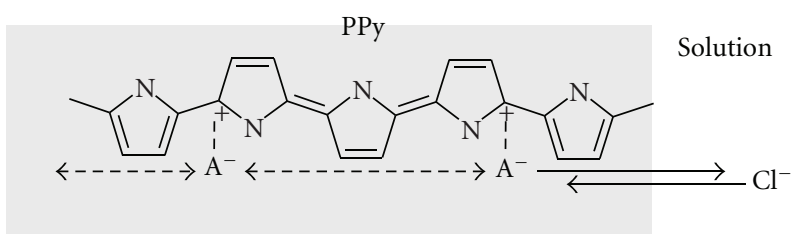

(a)

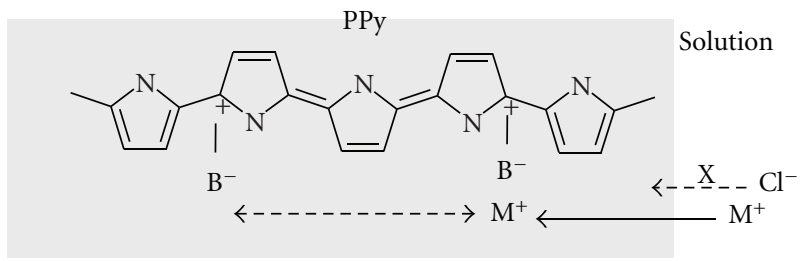

(b)

FIGURE 6: Ionic perm-selectivity of PPy film. (a) PPy film with anionic perm-selectivity, in which small-sized anions are doped in PPy and (b) PPy film with cationic perm-selectivity, in which largesized anions are doped in PPy film.

the doped anions are restricted to small value, reversely, the cations are dedoped out of and doped into the PPy during the oxidation and reduction, respectively. The dedoping process of cations in the PPy during the oxidation and the doping during the reduction are described in the following reaction (2):

$$
\begin{aligned}
& \operatorname{PPy}^{n+}\left(\frac{n}{x}\right) \mathrm{B}^{x-}+\left(\frac{m}{y}\right) \mathrm{M}_{\mathrm{aq}}^{y+}+m \mathrm{e} \\
& \rightleftarrows \mathrm{PPy}^{(n-m)+}\left(\frac{n}{x}\right) \mathrm{B}^{x-}\left(\frac{m}{y}\right) \mathrm{M}^{y+} .
\end{aligned}
$$




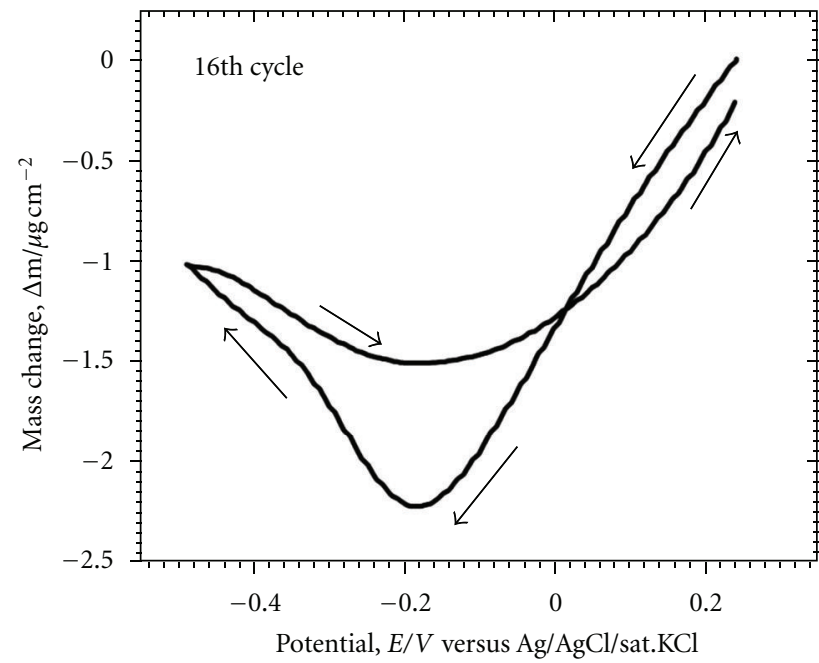

(a)

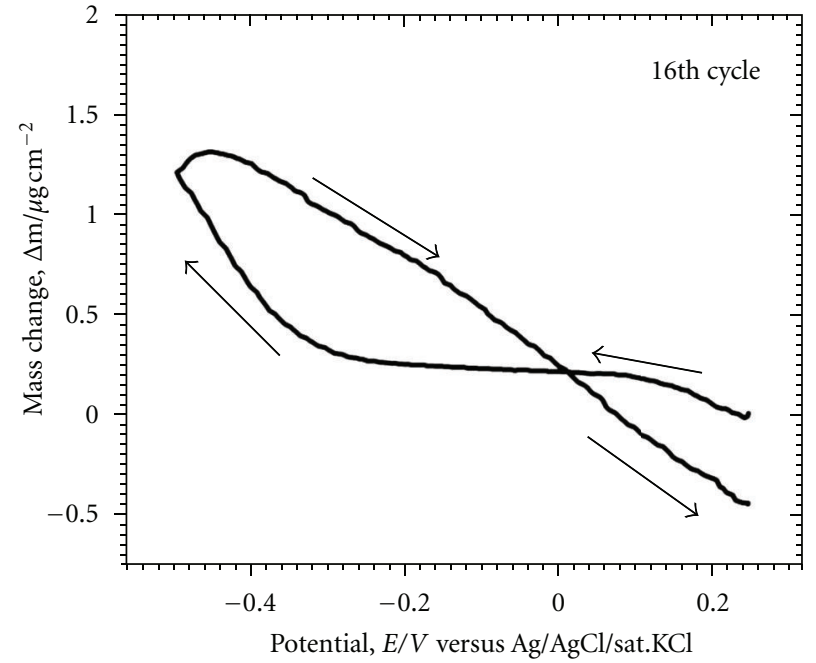

(b)

Figure 7: Mass change of the PPy-PMo layer and bilayer of PPy-PMo/PPy-DoS during the potentiodynamic reduction and oxidation in $3.5 \% \mathrm{NaCl}$ solution. The data was a result of the 16 th redox cycle.

When one considers the conducting PPy as a charged membrane, the immobile anions with large mass are assumed to have fixed sites with negative charge in the PPy. In the channel between the negatively charged sites, the cations can be mobile and the movement of the anions is greatly inhibited; that is, the membrane exhibits cationic permselectivity. As illustrated in Figure 6(b), under the situation where the dopant anions are large enough, the anions in the solution are excluded from the PPy and the substrate steel is protected against the pitting corrosion by chloride attack.

\subsection{Design for Corrosion Protection by the PPy. The anodic} protection greatly depends on the passivity and passive oxide on the steel. For the protection, the passivity and passive oxide must be kept stable. Further, the prevention of penetration of aggressive anions play an important role in the protection.

Deslouis et al. anodically prepared a PPy film on steel from an oxalate solution containing Py monomer and reported that the PPy layer protected the steel in sodium chloride solution for a long period [6-8]. They assumed that the ferric oxalate layer, which was formed underneath the PPy film by the polymerization, worked as a passivation film against corrosion. They also presented that the overcoat layer of PPy doped with dodecylsulfate, $\mathrm{C}_{12} \mathrm{H}_{25} \mathrm{OSO}_{3}{ }^{-}$(DoS), anions was effective to the corrosion protection and that a bilayer coating of PPy-oxalate/PPy-DoS could maintain the passivation state for longer than $500 \mathrm{~h}$, in which no corrosion products were observed.

DoS ion is a surfactant and forms micelle in aqueous solution at concentrations higher than critical concentration. Py monomers, which are probably incorporated in the micelle of DoS in aqueous solution, start to be polymerized when the micelles are collapsed on the electrode to which anodic potential is applied. DoS ions have relatively large masses and work as an immobile dopant in the PPy. The
PPy doped with DoS thus is considered as a membrane with negatively charged fixed sites and thus, with cationic permselectivity. The outer layer of PPy-DoS can, therefore, exclude the insertion of aggressive anions such as chloride ions.

In Figure 7 the mass change is plotted with anodic oxidation and cathodic reduction of a gold electrode covered with the PPy layers [9]. The mass change was measured by electrochemical quartz crystal microbalance (EQCM) with gold coating. The gold coating was covered by PPy doped with phosphomolybdate ions, $\mathrm{PMo}_{12} \mathrm{O}_{40}{ }^{3-}$ (PMo) and a bilayered PPy of PPy-PMo/PPy-DoS. The mass change of the PPy-PMo film in Figure 7(a) indicates the uptake of mass during the oxidation and inversely, the removal during the reduction. The behaviour of the mass change during the oxidation reflects the removal of electrons from the PPy and simultaneous insertion of anions from the electrolyte to the PPy and viceversa during the reduction. When one introduces the outer layer of PPy-DoS, the mass change is inversely different from the above result, as shown in Figure $7(\mathrm{~b})$. During the oxidation the mass increases and during the reduction it decreases. In PPy-DoS layer, in which negatively charged ions are fixed, the cations are mobile; during the oxidation the simultaneous removal of both electrons and cations from PPy and during the reduction viceversa. It can be understood that the PPy doped with DoS functions as a cationic perm-selective membrane.

Kowalski et al. designed the corrosion protection PPy layer of steels as following [9-14]. For the inner layer, the PPy was doped with PMo. PMo works as a passivator which stabilizes the passive state of steels and facilitates the formation of passive oxide. For the outer layer, the PPy doped with DoS was prepared. The outer layer can inhibit the anions from penetrating in the PPy layer. The results by Kowalski et al. are shown in Figure 8, [13] where the open circuit potential of the steel covered with the bilayered PPy is plotted during the immersion in $3.5 \%$ sodium chloride 


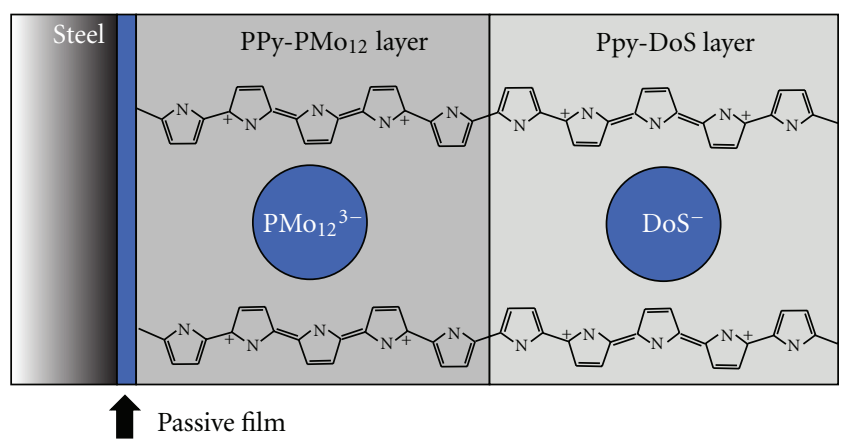

(a)

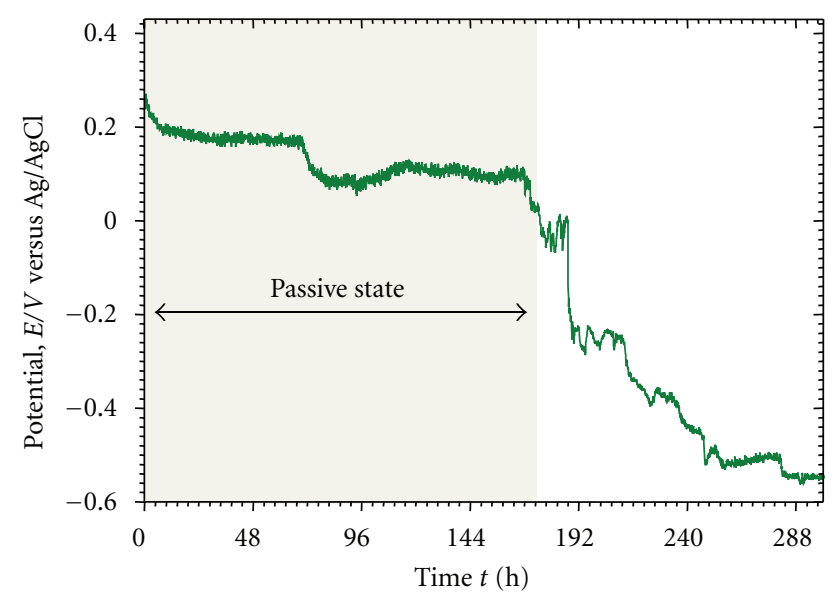

(b)

Figure 8: Model of bilayered PPy film and transient of open circuit potential of steel covered by the bilayered PPy in $3.5 \% \mathrm{NaCl}$ solution.

solution. The steel covered with the bilayered PPy, about $5 \mu \mathrm{m}$ thick consisting of PPy-PMo/PPy-DoS exhibited the passivation for $190 \mathrm{~h}$ in which no corrosion products were observed. If the steel was covered with a single PPy-DoS layer of the same thickness, the passivation is kept for $10 \mathrm{~h}$. It is assumed that PMo ion doped in the inner PPy stabilizes the passive oxide and helps the maintenance of the passive state of the substrate steel.

The design which combines the inner layer stabilizing the passive oxide with the outer later inhibiting anions from penetrating through PPy to the steel may be suitable to the corrosion protection of steel.

3.4. Self-Healing Property. In the corrosion protection, the coating must tolerate small defects to be considered as a suitable replacement for chromate-based coatings. We expect for the conducting polymer coating a self-healing property in which the passive oxide is spontaneously repaired after it develops small defects. On the chromate coating, the chromate ions dissolved from the coating oxidize the steel surface at the damaged sites to reform the passive oxide

$$
2 \mathrm{Fe}+2 \mathrm{CrO}_{4}{ }^{2-}+4 \mathrm{H}^{+} \longrightarrow \mathrm{Fe}_{2} \mathrm{O}_{3}+\mathrm{Cr}_{2} \mathrm{O}_{3}+2 \mathrm{H}_{2} \mathrm{O} .
$$

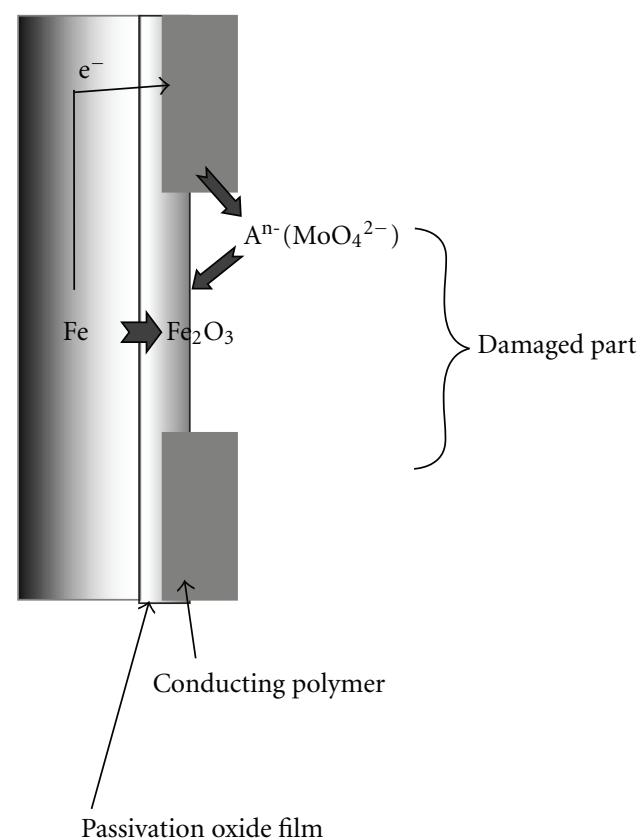

FIGURE 9: Schematic model of self-healing property of PPy$\mathrm{PMo}_{12} / \mathrm{PPy}$-DoS bilayered PPy. Molybdate anions, dissolving from PPy film, reform a passive oxide at the damaged part.

A self-healing model proposed by Kowalski et al. is shown in Figure 9 for the bilayered PPy of PPy-PMo/PPy-DoS [9]. After the coating and passive oxide were locally flawed, PMo in the PPy layer is hydrolyzed and decomposes to molybdate and phosphate ions, and then both ions reach the flawed sites. The molybdate ions react with ferric ions on the flawed site to produce the ferric molybdate film. The salt film may be gradually changed to the passive oxide on the damaged site

$$
\begin{gathered}
\mathrm{Fe} \longrightarrow \mathrm{Fe}^{3+}+3 \mathrm{e} . \\
2 \mathrm{Fe}^{3+}+3 \mathrm{MoO}_{4}{ }^{2-} \longrightarrow \mathrm{Fe}_{2}\left(\mathrm{MoO}_{4}\right)_{3} .
\end{gathered}
$$

Figure 10 shows the results reported by Kowalski et al. in which a small flaw was inserted by cutting knife in $2 \mathrm{~h}$ during the immersion in $3.5 \%$ sodium chloride solution [9]. After the PPy layer received the small flaw, the open circuit potential temporarily fell down. When the corrosion continues at the defect site, the potential will decrease to that of bare steel. The potential, however, rose up and recovered in the passive potential region. After that, the potential maintained the high potential in the passive region. When the flawed local site was measured by Raman scattering spectroscopy under this situation, the molybdate salt was detected [9]. It was found that a salt layer of ferric molybdate was reformed on the site.

\section{Summary}

Many papers on the corrosion protection by conducting polymer have been published since 10 years. In those, 


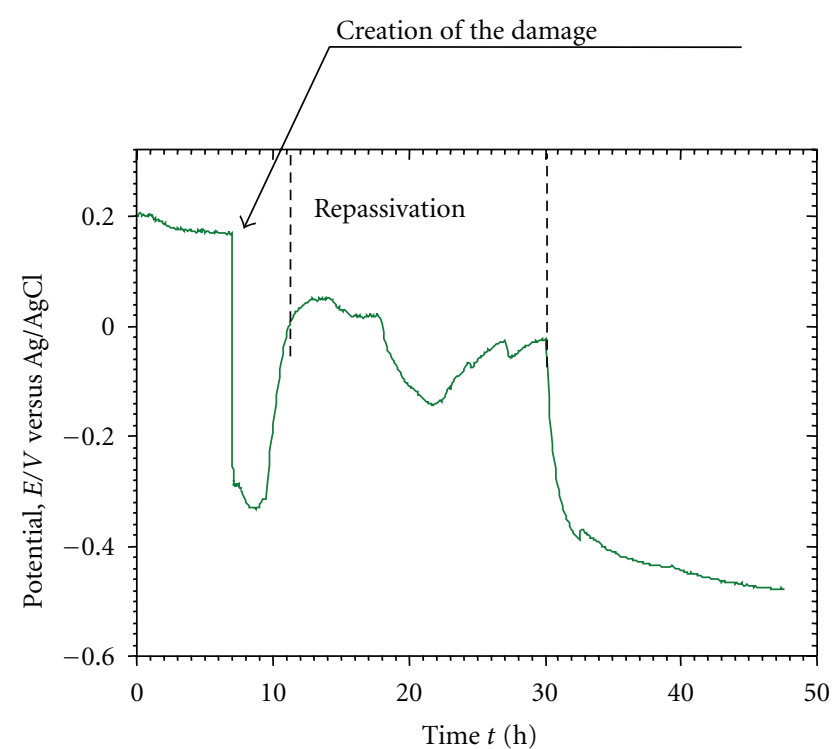

Figure 10: Potential change of steel covered by bilayered PPy film during the immersion in $3.5 \% \mathrm{NaCl}$ solution. The damage was inserted on the PPy layer by a small knife in $7 \mathrm{~h}$.

the attention was paid to how to form homogeneous and adherent layers of conducting polymer on steels and other metals. For the corrosion protection, we must consider the design of the conducting polymer. Since the corrosion protection by the conducting polymer is based on the anodic protection mechanism, we must consider how to stabilize the passive oxide underneath the polymer layer and how to inhibit the aggressive anions from penetrating the polymer layer.

Two mechanisms have been considered for the corrosion protection; one is physical barrier model and the other anodic protection model. We assume that the barrier effect suppresses the active dissolution of steel, facilitating the potential to be shifted in the passive region. The oxidative capability of the conducting polymer helps the potential shift and long maintenance of the passive state of the steel.

Our bilayered model, designed for the corrosion protection, includes two important factors: one is stabilization of the passive film on the steel by action of dopant ions in the inner PPy layer and the other is control of ionic permselectivity by organic acid ions doped in the outer PPy layer.

\section{References}

[1] C. K. Chiang, C. R. Fincher, Y. W. Park et al., "Electrical conductivity in doped polyacetylene," Physical Review Letters, vol. 39, no. 17, pp. 1098-1101, 1977.

[2] D. W. DeBerry, "Modification of the electrochemical and corrosion behavior of stainless steels with an electroactive coating," Journal of the Electrochemical Society, vol. 132, no. 5, pp. 1022-1026, 1985.

[3] B. Wessling, "Passivation of metals by coating with polyaniline: corrosion potential shift and morphological changes," Advanced Materials, vol. 6, no. 3, pp. 226-228, 1994.

[4] D. E. Tallman, G. Spinks, A. Dominis, and G. G. Wallace, "Electroactive conducting polymers for corrosion control:
Part 1. General introduction and a review of non-ferrous metals," Journal of Solid State Electrochemistry, vol. 6, no. 2, pp. 73-84, 2002.

[5] E. M. Genies, G. Bidan, and A. F. Diaz, "Spectroelectrochemical study of polypyrrole films," Journal of Electroanalytical Chemistry, vol. 149, no. 1-2, pp. 101-113, 1983.

[6] H. Nguyen Thi Le, B. Garcia, C. Deslouis, and Q. Le Xuan, "Corrosion protection and conducting polymers: polypyrrole films on iron," Electrochimica Acta, vol. 46, no. 26-27, pp. 4259-4272, 2001.

[7] N. T. L. Hien, B. Garcia, A. Pailleret, and C. Deslouis, "Role of doping ions in the corrosion protection of iron by polypyrrole films," Electrochimica Acta, vol. 50, no. 7-8, pp. 1747-1755, 2005.

[8] T. Van Schaftinghen, C. Deslouis, A. Hubin, and H. Terryn, "Influence of the surface pre-treatment prior to the film synthesis, on the corrosion protection of iron with polypyrrole films," Electrochimica Acta, vol. 51, no. 8-9, pp. 1695-1703, 2006.

[9] D. Kowalski, M. Ueda, and T. Ohtsuka, "Self-healing ionpermselective conducting polymer coating," Journal of Materials Chemistry, vol. 20, no. 36, pp. 7630-7633, 2010.

[10] T. Ohtsuka, M. Iida, and M. Ueda, "Polypyrrole coating doped by molybdo-phosphate anions for corrosion prevention of carbon steels," Journal of Solid State Electrochemistry, vol. 10, no. 9, pp. 714-720, 2006.

[11] D. Kowalski, M. Ueda, and T. Ohtsuka, "Corrosion protection of steel by bi-layered polypyrrole doped with molybdophosphate and naphthalenedisulfonate anions," Corrosion Science, vol. 49, no. 3, pp. 1635-1644, 2007.

[12] D. Kowalski, M. Ueda, and T. Ohtsuka, "The effect of counter anions on corrosion resistance of steel covered by bi-layered polypyrrole film," Corrosion Science, vol. 49, no. 8, pp. 34423452, 2007.

[13] D. Kowalski, M. Ueda, and T. Ohtsuka, "The effect of ultrasonic irradiation during electropolymerization of polypyrrole on corrosion prevention of the coated steel," Corrosion Science, vol. 50, no. 1, pp. 286-291, 2008.

[14] D. Kowalski, M. Ueda, and T. Ohtsuka, "Self-healing ability of conductive polypyrrole coating with artificial defect," ECS Transactions, vol. 16, no. 52, pp. 177-182, 2008. 

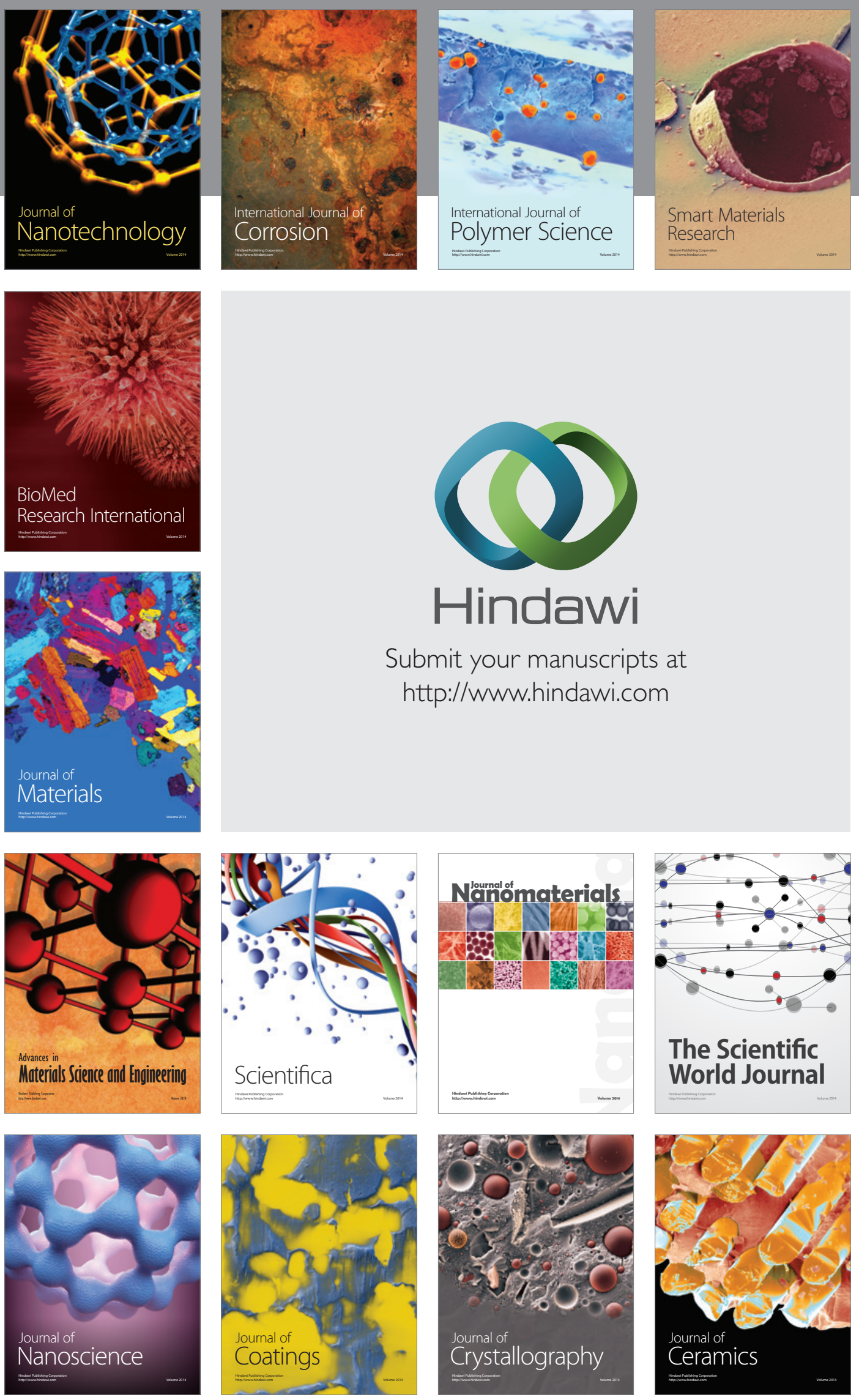

The Scientific World Journal

Submit your manuscripts at

http://www.hindawi.com

\section{World Journal}

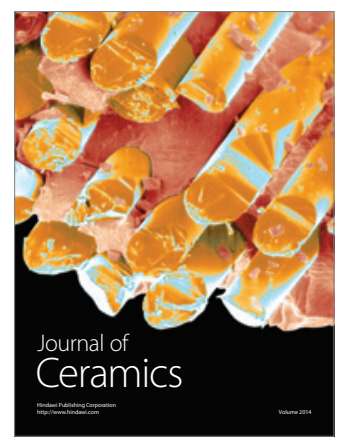

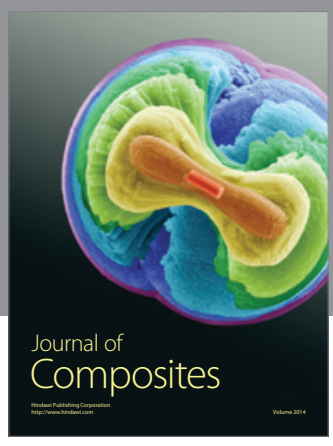
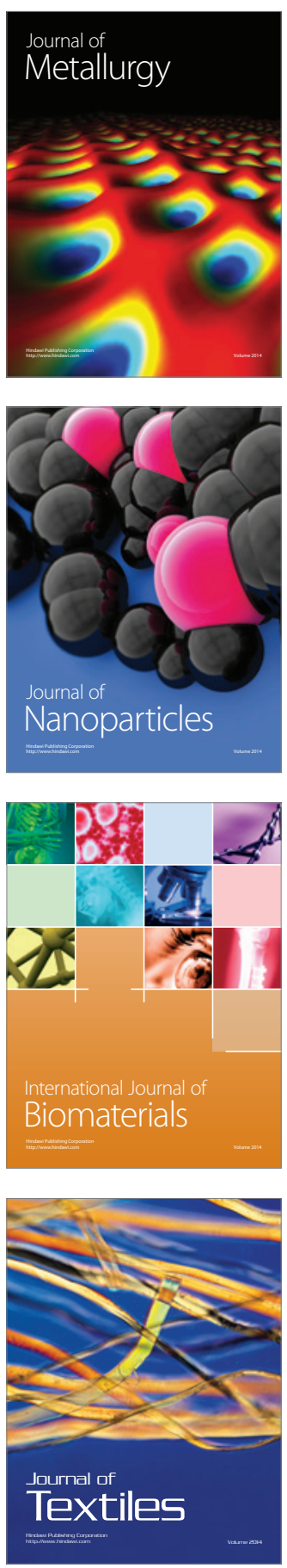